\title{
Addressing the United Nations' Sustainable Development Goals in Germany
}

\author{
Jocelyn Sorensen, Faculty \\ JocelynSorensen@westcliff.edu
}

\begin{abstract}
This paper takes a critical look at the United Nations' sustainable development goals in regard to Germany. This paper will further examine three of the seventeen goals laid out for 2030 focusing on determining what efforts and proposed solutions towards ending poverty, eradicating hunger and achieving gender equality are undertaken. The issues of poverty, hunger and gender equity are an additional source of tension for Germany as they seek to address these concerns domestically while acting as a responsible leader internationally.
\end{abstract}




\section{INTRODUCTION}

Delicate political coalitions, a leading geopolitical position, and a complicated troubled past make Germany a country of tensions and complexities. A proud Kulturnation, Germany remains willfully ignorant of its historic heterogeneous makeup, its role in the history of migration flows and its economic need for immigrants. As a social-democratic state, Germany constantly strives to maintain a delicate tension. It is a generous welfare state working in conjunction with a free-market economy guided by social policies. Germany is a leading actor in the European Union. Its powerhouse economy, for which Chancellor Angela Merkel has achieved both fame and infamy, is centered around Germany's economic surplus. Economic optimism is held in tension with social anxiety about the effects of the large numbers of asylum seekers and the rise of racist nationalists into parliamentary positions in the recent election. Germany's election in September 2017 exposed racist and xenophobic movements that had been building over time, resulting in a historic upset of party coalitions. As Germany moves forward, it must confront its (re-)emerging internal conflicts as it continues to navigate and lead on the global stage.

Confronting these tensions and conflicts, Germany is taking a leading role by evaluating and constructing solutions working toward the goals set forth by the United Nations' seventeen sustainable development goals targeted for the year 2030. This paper will look at three of these goals in the case of Germany, focusing on the challenges of ending poverty, eradicating hunger, and achieving gender equality as well as their proposed solutions. The issues of poverty, hunger and gender equity are an additional source of tension for Germany as they seek to address these concerns domestically while acting as a responsible leader internationally.

\section{ENDING POVERTY}

The United Nations has created the following sustainable development goals for Germany, "Ending Poverty" and "Zero Hunger." Unsurprisingly, there is tension involved when talking about poverty in Germany, or any other affluent country with a robust welfare state for that matter. The existence of poverty in a country with a welfare state and an economic surplus is counterintuitive. It is almost unthinkable to speak of poverty in Germany (or any other Western European country) when there are other regions which encounter much more extreme forms of poverty. The World Bank is central to the examination and documentation of poverty world-wide.

Germany has been a key member of the World Bank since 1952 ("EDS05 Home," n.d.), and yet, is largely excluded from World Bank reports that discuss poverty. These reports focus on new European Union (EU) member states and other countries in southeastern Europe which are in far worse economic condition than those in western Europe. It is the comparison of Germany with developing countries in Africa, the struggling Balkan nations, and even with other weaker EU member states like Greece that contribute to the denial of the existence of German poverty (Pfeiffer, 2014). Public trust in the welfare state is extremely high in regard to its provision for those in need. These multiple layers of denial have rendered poverty in Germany largely invisible. Thanks to more recent social and economic shifts, Germany is becoming increasingly aware of its perpetual problems in this area while also coming to a deeper, more convicting understanding of its role globally. In particular, the country is coming to grips with the effects of German colonialism as well as 
the effects of the German industry on the global South. German recognition of its complicity in the poverty cycle parallels the nation's efforts to take a more proactive role in assisting developing countries.

Though poverty and hunger exist throughout German society, the media's attention on the subject is not mainstream, occluded by other highly politicized issues such as immigration and corporate tax evasion. In the affluent state of Germany, the question of poverty is not whether the population suffers abject, or "extreme" poverty, but of the increasing inequalities that push wage-earners further and further from the established standard of living. Official estimates state that $16.7 \%$ of the population falls below the poverty line ("Population below poverty line," n.d.). Poverty is defined in the region as those who are living at or below $60 \%$ of the average gross income of the country's population (Meyer-Rosenfeld, 2013). Many experts argue that this designation is an arbitrary one and does not properly capture the complexities, as there is a high variance of living costs across the region (Simler, 2016). The Organization for Economic Co-operation and Development (OECD) complicates the understanding of poverty in Germany by defining the poverty rate as:

the ratio of the number of people (in a given age group) whose income falls below the poverty line; taken as half the median household income of the total population. It is also available by broad age group: child poverty (0-17 years old), working-age poverty and elderly poverty (66-year-olds or more). ("Inequality - poverty rate," n.d., para. 1)

The comparison between EU states also obfuscates the actual experience of poverty as, "two countries with the same poverty rates may differ in terms of the relative income-level of the poor" ("Inequality-poverty rate," n.d., para. 1). OECD data measures poverty as those living at $50 \%$ of the median income, rather than $60 \%$, lowering the statistic of those living in poverty substantially.

Multiple populations have been shown to be particularly vulnerable to poverty for several systemic reasons. As will be demonstrated in the following discussion, these populations include single mothers, children, and female pensioners. Even in a powerhouse economy like Germany, poverty has a feminine face. Poverty is predominately measured at the household level. This measurement is both useful and problematic as it reveals the gender gap in poverty:

In households with an adult couple, either both partners are in poverty or neither is in poverty. So, if all adults are married or cohabiting with a person of the other sex, there would be no sex gap in poverty. Thus, the gender gap exists because single women are poorer than single men (Christopher, England, Smeeding \& Philips, 2002, p. 5).

This is problematic because it removes all nuance of the female experience of cohabiting with men, assuming equal access to resources, and thus, equal quality of life. Single mothers are more vulnerable to poverty for several distinct reasons. Single mothers are shown to be more likely to live with children than single fathers. Additionally, women earn lower wages than men due to their greater presence in the service sector and the persistent gender pay gap (Christopher, England, Smeeding \& Philips, 2002). Motherhood has also shown to be a factor for reduced income as women either stop working, reduce their hours or change occupations, further increasing the male-female pay gap (Christopher, England, Smeeding \& Philips, 2002). 
Though the German government provides child support to mothers when fathers are absent, research shows that government social transfers and tax breaks do little to reduce gendered poverty (Christopher, England, Smeeding \& Philips, 2002). Women are also less likely to pursue their rights for child support in court, thus increasing their vulnerability as they only receive government support if the father is not able to pay or is unknown (Klammer, 2009). Children are naturally subject to poverty determined by their parents' situations. Notably, children living in poverty suffer from social stigma and social exclusion in their educational experiences (Klammer, 2009).

A population often neglected in poverty research is pensioners. The feminization of poverty persists even into retirement age, and especially late retirement. European Union research illuminates the risk of poverty amongst pensioners in stating that, "Gender differences in the at-risk-of-poverty rate among those aged 75+ are fairly large, even though there are hardly any differences among the younger pensioners" (Ahornen \& BachOthman, 2010, p. 13). Widows tend to outlive their husbands and live alone on pensions, which is shown to be connected to their vulnerability regarding poverty (Ahrnen \& Bach-Othman, 2010). Women have lower pensions on average than men, largely because they work less due to child-rearing and earn less on average than their male counterparts (Sellach \& Ender-Dragässer, 2000). Pensions were set at their retirement age and have not until recently been adjusted for inflation. This has been an area of debate in the last couple decades as the introduction of the euro plus continued inflation and rising costs for housing and food have put strain on the population as a whole (Boersch-Supan \& Wilke, 2006). When the euro was introduced, prices were not adjusted properly, but transferred directly over from Deutsche mark to euro, devaluing savings. The elderly in the east of Germany feel this most acutely. The exodus of workingage Germans to the west after reunification left those who stayed susceptible to poverty. Though much effort has been made to invest in the east's economy, much of this is centered in just a few urban areas, namely Berlin, Leipzig and Dresden (Nipper, 2002; Bontje, 2005). Those who owned a rural home in the east and stayed through retirement found themselves in increasing distress, often without ready access to healthcare or food as the sparse, aging rural population does not substantially contribute to a tax base to sustain the basic infrastructure.

\section{SYSTEMIC ECONOMIC STRUCTURES}

Even within a thriving economy as is the case in Germany, weak points exist and implemented measures of reform often have unintended consequences. The legislation reform in Germany passed in the early 2000's was known as "Agenda 2010." This was introduced in an effort to combat high rates of unemployment and a sluggish economy. This legislation introduced some new employment options intended to increase full-time employment. The bulk of the legislation dealt with part-time employment, which up until that point had been very limited in the German economy (Somaskanda, 2015). Flexible parttime employment was introduced and deregulated. The idea was that access to parttime work was better than no work and would effectively lead to full-time employment (Somaskanda, 2015). Unfortunately, an increase in full-time employment did not come to fruition, but instead created a growing culture of temporary part-time work. The core of the workforce in Germany, which makes up the middle class, has remained strong through this shift, though this may change when the current generation retires. The reform packet 
introduced, among other things, the mini-job, which allows for an employee to earn up to 450 euro per month tax-free. This was intended to supplement incomes. Instead, people started working several mini-jobs to make ends-meet, and employers began offering mostly mini-job positions because they did not have to provide the same employment benefits or taxes required by the state. The deregulation of this type of job classification led to instances of exploitation, especially considering that there was no minimum wage in Germany at this time. Poverty increased through this mechanism.

Because the economy and labor force are highly regulated and access to work and the welfare state is limited, the informal sector is precarious, largely invisible, and not captured in official statistics. Acknowledgement of the informal sector is important to uncovering the invisible exploitation that increases the already recognized statistics on poverty in Germany. Susceptible to this type of exploitation are those who find themselves on the edge of society for some reason. Women, and men, from other EU countries who have residency in Germany but not citizenship are an example. If these EU citizens do not formally register their residency in Germany, they are not properly captured in government statistics and are often working in the low wage sector. Those who have overstayed their visas or entered illegally also find themselves in similar positions, though they find themselves under greater pressure from employers as any slipups could potentially trigger an employer to anonymously call immigration services.

Another vulnerable population that often finds themselves in situations of exploitation are asylum seekers who are in limbo until their case is decided upon. In this state of limbo, they do not have the right to work, and thus, rely on support from the government. This support is so little that they are never able to invest in their future. In many cases as little as 40 euro a month is given in addition to housing and food subsidies. Taking an honest look at the structural loopholes and informal economy without criminalizing those experiencing poverty and exploitation within it is a necessary first step in working towards productive solutions to ending poverty and discrimination in German society.

\section{No hunger}

Addressing hunger in Germany is difficult as research on the topic is still in a nascent stage. To begin with, there is no centralized data collection on hunger in Germany by either the state or academic researchers (Pfeiffer, 2014). Pfeiffer (2014) reports that limited research has been done by a select few, but the insight and knowledge gained pales in comparison to effective and extensive research done in other western nations such as the United Kingdom and United States, and as a result, its impact on policy making has been limited (Pfeiffer, 2014). The most recent survey was completed from 2005 to 2007, examining the eating habits of 20,000 people using various methodologies. Though the results are not helpful in creating legitimate estimations of food poverty or hunger in Germany, they revealed some counterintuitive realities that illuminate the importance of pursuing access to healthier food in addition to universal access (Pfeiffer, 2014).

Pfeiffer (2014) has done significant research on food poverty in Germany and sees food as more than just a physical need. Pfeiffer (2014) offers the definition of hunger as, "physically palpable poverty" (p. 5). She argues that while hunger occurs in Germany, food poverty is more than just making sure that a certain number of calories are present in a diet, arguing that food has a socialpsychological component, and is, in fact, "deeply social" in German society, and thus, 
deeply related to social inclusion/exclusion, which is a central concern in the fight to end poverty (Pfeiffer, 2014). Pfeiffer (2014) argues that, "Food is essential to participation and sociality, a central source of social capital in an individualized society" (p. 3). Those who live under the poverty line do not have expendable income to purchase food in social settings important to building relationships in German society. Going to lunch or a pub after work with colleagues or brunch with friends is important for both professional and personal relationships. Not being able to participate in such social activities, excludes a person from potential job opportunities and from friend circles, among other things in a society where it is taboo to speak of finances. Exclusion from social settings can easily translate to exclusion from professional ones.

The government has shifted responsibility for food security away from itself, delegating it to the private sector and to existing religious and moral impetus (Pfeiffer, 2014). The result of this shift was the establishment of food distribution centers and food banks. Many of these entities are run by volunteers and rely on donations. They provide meals for both adults and children during school hours for those who not receive sufficient or reliable food provision at home. Because of their reliance upon volunteers and donations, the food banks work well as a point of emergency assistance but should not be relied upon for long-term assistance (Pfeiffer, 2014). Research shows that every year 1.5 million people attend 900 food banks and 3000 food distribution centers across Germany, half of which are regular customers (Pfeiffer, 2014).

Achieve gender equity and empower all women and girls

We all committed ourselves in 1995 to implement the Beijing Platform for Action. Now we are making a new commitment with Sustainable

Development Goal 5. Commitments are good. Action is better. Let us take action! (Merkel, 2017)

The feminization of poverty is a pattern that has developed within the German welfare state. Intricately enmeshed in the issue of poverty is the prevalent gender inequality that persists despite decades of feminist thought and influence. In the reunification process of east and west Germany, it was west German culture that was given credence rather than that of east German culture. Those in the east of Germany had been accustomed to a greater degree of equality due to policies of full employment and quota systems, even though women experienced the double burden of fulltime employment and full-time domestic work as wife and mother (Skard, 2015). Women were encouraged to be in the home as caretakers, and policies focusing on the family were extended, including those mentioned in the above sections. These policies, though heavily supported by the general population, have recently been critiqued as having a "retraditionalising effect," reinforcing traditional gender roles and norms instead of focusing on policies targeting equity (Botsch, 2015, p. 5). The report on women's rights and gender equality rates Germany's performance in this area as "mediocre" (Botsch, 2015). Chancellor Merkel's (2017) declaration of action has picked up more speed than in previous years, though much is left to be desired. Discussions on gender equality in Germany focus largely on the percentage of women in leadership positions, gender pay gap and labor market participation, and female interest and participation in subject matter in secondary schools, notably, STEM fields.

Research on gender divisions in the labor force reveals that there exists both a "horizontal" and "vertical segregation" 
(Botsch, 2015, p. 4). "Horizontal segregation" is the distinct segregation of men and women across occupations, each being overrepresented in their respective gender typical professions (e.g. women in the service sector, men in science and engineering) (Botsch, 2015, p. 4). "Vertical segregation" refers to a lack of women in management positions (Botsch, 2015, p. 10). The European Commission believes that "equal participation of women and men in decision-making positions is a matter of justice, respect for fundamental rights and good governance" ("2017 report on equality," 2017, p. 28). One of the platforms for important decision-making is government. Representation of women elected into the Bundestag and at the federal state level "has remained about one-third for over ten years," but increased to $37 \%$ by 2017 ("2017 report on equality," 2017, p. 32). This level of representation is largely responsible for why the issue of gender inequality has not been a higher priority within the country. It is at the municipal level that women's representation at $26 \%$ falls below the EU average of $35 \%$ ("2017 report on equality," 2017).

Another platform for influential decisionmaking is corporate management. Compared to the federal government, it is in the private sector that women are far more underrepresented. Supervisory boards are shown to have increased their percentage of women over the years to just $19 \%$, while at the executive level, women make up only $6 \%$ of board members ("The current situation," 2012). The EU Commission has determined that countries with specific legislation targeting an increase in the number of female board members in large stock-listed companies have seen more success in attaining better representation of women than those without ("The current situation," 2012).
Labor market participation and the persistent gender pay gap produce mixed messages on the state of gender equality in Germany. Labor market participation is up but little progress has been made on closing the pay gap in recent years ("The current situation," 2012). In fact, between 2010 and 2014, no progress was made at all ("The current situation," 2012). The factors measured to determine labor market gender inequality, apart from the segregation of that labor market, are levels of employment, the predominance of atypical work (e.g. parttime), and the gender pay gap. The European Commission's report on gender equality (2012) demonstrates that Germany is a relatively poor performer in this respect, standing at $45 \%$ labor market inequality. The report also shows that the gender pay gap, gender hours gap (i.e. unpaid work such as caretaking), and employment gap are all greatly contributing to inequality ("The current situation," 2012). The employment gap is the least problematic in Germany as more and more women are joining the workforce in some capacity. As we saw in the horizontal segregation of the labor market, however, where women enter the market is largely related to their educational choices and attainment. The dominance of traditional family formation and gender roles still heavily influences choices and opportunities/barriers to the nature of work for women. Legally, equality is required. Yet barriers to women continue to persist, especially in the typical areas of family formation and retirement (Botsch, 2015). Women continue to be the primary caregivers for children and the elderly, especially as positions in state-run day care centers are limited. This unpaid work results in women either not working or working parttime. As of $2011,45 \%$ of German women were working part-time instead of full-time, higher than the EU average ("The current situation," 2017). The percentage of women working 
part-time is significant considering that $75 \%$ of German women between the ages of 20 and 64 are employed ("2017 report on equality," 2017). Determining equality encompasses factors such as economic independence, which takes the employment rate into account as well as "the number of paid working hours, which better reflects work intensity" ("2017 report on equality," 2017, p. 12).

Unpaid work for women total, on average, almost the number of hours that an average woman works a part-time job. Women work an average of 29 hours per week while doing 20 hours of unpaid work, while men work 38 and 7 hours, respectively ("2017 report on equality," 2017). Gender norms, gender relations and family formation are currently in shift. Women are marrying later and having less children. Though divorce is a lengthy and expensive process in Germany, it is becoming more common. Blossfield (1995) explains that, "the distinction between marital and nonmarital child-bearing, and between marriage and cohabitation, are losing their normative force and divorce tends to become more of an option than a violation of social norms" ( $p$. 201). Optimistically, Blossfield (1995) claims that the "expansion of the welfare-state-based extra familial institutions...provide alternative sources of material security, personal services, satisfaction, and leisure" (p. 201). Social exclusion due to the stigma of divorce may be disappearing, but it is crucial to note that the vulnerability of women and children should not be minimized or hidden by the seemingly generous welfare state provisions.

\section{Strategic Solutions to Meet SDGs in 2030}

The German parliament published a set of strategic solutions in a social report in 2015 as a path for moving forward with a domestic agenda to achieve the UN sustainable development goals by 2030 ("Strategische Ssozialberichterstattung," 2015). To address the issue of poverty, and ultimately other goals in the process, the parliament committed to a range of initiatives, expansions of current policies, and investments. One of the first steps toward fighting poverty was the institution of a minimum wage ("Strategische Ssozialberichterstattung," 2015). This was introduced gradually, first applying to only a few service jobs, such as taxi drivers and hairdressers, but now has been extended to almost all jobs, although there still exists a few exceptions. Minimum wage began at $€ 8.50$ but was increased to $€ 8.84$ by the following year "Strategische Ssozialberichterstattung," 2015). This is extremely advantageous for women living in rural areas and less so for those in expensive urban locations due to higher costs of living. Pensions were also given a slight increase to adjust for inflation starting in 2014 and are intended to continue to increase as deemed appropriate. More importantly, commitments to increases in pensions, will bring advantages to women specifically, as there is a greater recognition of and compensation for time spent raising children ("Strategische Ssozialberichterstattung," 2015).

A couple of campaigns were initiated to attempt to address the gender wage gap. "Equal Pay Day" was a public campaign that worked to encourage transparency in wages for men and women ("Strategische sSozialberichterstattung," 2015). A second initiative is a project entitled, "Was verdeint die Frau? Wirtschaftliche Unabhängigkeit!" (What does a woman earn? Economic independence!). This project took place from 2014 to 2016. This project worked to educate women on the issues of which they should be aware regarding their professional lives, concentrating on transitional periods in their resume due to childbirth, education, etc., which persist as barriers to meaningful and rewarding work ("Strategische Ssozialberichterstattung," 2015). 
One of Germany's efforts toward gender equality is participation and implementation of an EU practice called gender mainstreaming, which:

involves ensuring that gender perspectives and attention to the goal of gender equality are central to all activities-policy development, research, advocacy, dialogue, legislation, resource allocation, and planning, implementation and monitoring of programmes and projects ("Gender mainstreaming," n.d., para. 1).

The EU Commission and German governments have chosen to tackle these issues from a gendered perspective, focusing specifically on women, supporting the more traditional roles of women in the same breath as advocating for equality in value. A number of projects focusing on gender equality have been reported. The "equal treatment check" is undergoing development, which will result in a set of analytical tools to be utilized by employers, boards, and other supervisory entities to assess whether the law of gender equality in hiring practices and working conditions is being upheld ("2017 report on equality," 2017, p. 13).

As childbirth has proven a barrier for women when re-entering the workforce, the German government has implemented two discrete actions to address this issue and to work toward towards gender equality. The Development Policy Action Plan on Gender Equality 2016-2020 increases state-funded childcare, allowing for women to return to work much more quickly than was previously possible ("Germany pledges to expand support," n.d.). Parental leave has also intentionally been extended for men, as it has proven to contribute to more active fathers ("2017 report on equality," 2017, p. 17). Men now receive 9 weeks of paid leave ("2017 report on equality," 2017). This is intended to incentivize the sharing of childcare and other domestic work.

One of the most important and prominent pieces of legislation passed recently was the Act on Equal Participation of Women and Men in Leadership Positions in the private and public sector. This act requires 3500 businesses to create goals to "increase [the] proportion of women on their boards and at several management levels" ("Germany pledges to expand support," n.d., para. 5).

Also, as of 2016, a gender quota of $30 \%$ for supervisory boards for stock-listed companies is required ("Germany pledges to expand support," n.d.). Initiatives to increase entrepreneurship for women have been passed as an additional effort to close gender employment and earning gaps. In Mecklenburg-Pomerania, for example, an initiative was passed enabling women to obtain loans from state investment banks whose loan applications had been previously rejected by other banks (Sattar, 2015).

\section{CONCLUSIONS}

There is much to be done domestically to end poverty in Germany. Thankfully, Germany has many stable systems already in place and has already achieved a relatively high level of affluence, even among its poorest. With enough public commitment to taxes and expansion of social programs, eradication of poverty, or more realistically great reduction in poverty is arguably within reach by 2030 . The more Germany opens access to the labor market, the more transparency and protection can be extended to those at risk of poverty. This includes opening the labor market further to immigrants and refugees, who are among the country's most vulnerable.

Though poverty affects women more broadly than it does men, the current trajectory of poverty development is not 
toward a further feminization of poverty, but rather an increase in the poverty experienced by men. Although the statistical gap between men and women is indeed closing, often interpreted as progress, the overall picture is not as optimistic. Evidence points to an increase in income inequality in society, not just for women. Men are experiencing a feminization of work, meaning that men will now experience more periods of interrupted work throughout their careers, causing an increase in poverty experienced by men (Klammer, 2015).

Food banks have played a key role in alleviating food poverty. However, they are not a viable long-term solution as they receive no state funds and are dependent upon both volunteers and donations to function. After much scandal in the past, a deep vein of skepticism and suspicion runs through German society, making donations hard to come by, be it for blood drives, homeless assistance, or food banks. A certain level of public oversight and trust will have to be re-established before the private sector can truly take the reins of being a stable support system that can not only meet needs sufficiently but can effectively assist clients in bettering their financial states. Research in the area of hunger, is absent and thus, is essential. Only in the past year has the government even begun to acknowledge that there might be something to address in this area. The first step of acknowledging the problem has been taken; now funding and experts are needed to step in to provide some reliable and tangible data on the subject for the appropriate governmental policies to be created and implemented.
Workers who have been unemployed longterm will experience delays in being incorporated into the work force. The hiring process and criteria are very rigid across all sectors.

Officialness and detailed documentation is part of the fabric of German culture and society and works to exclude competent workers from finding employment. Even entry-level grocery store cashiers must obtain an official job training certification prior to work. Changing these processes will take much effort and time. Even equipping those who have been unemployed long-term with job skills, trying to fill-in the gaps of education, and training for interviews will not destroy the stigma associated with being unemployed nor will these efforts bring about a rapid change in hiring expectations or standards. Instead, this will entail a long-haul effort to create a cultural shift in the labor market. An additional challenge to addressing the gender pay gap is the cultural taboo of talking about money in general, and salaries specifically. In addition, most companies in Germany currently have non-disclosure agreements on all salaryrelated issues. Forcing companies to make their hiring practices and salaries transparent is crucial to gender equality efforts, and equally difficult to accomplish.

Ultimately, the greatest challenge to addressing gender inequality and poverty in Germany is to stop comparing the poor in Germany to the impoverished in places like Africa and the Indian subcontinent. These comparisons in conjunction with the national confidence and reliance upon the welfare state, hide these inequalities and prevent appropriate action from taking place. 


\section{REFERENCES}

Blossfeld, H.P., De Rose, A., Hoem, J. M., \& Rohwer, G. (1995). Education, modernization, and the risk of marriage disruption in Sweden, West Germany, and Italy. In K. Oppenheim Mason \& A. Jensen (eds.), Gender and Family Change in Industrialized Countries (pp. 200-222). Oxford, GB: Clarendeon Press.

Boersch-Supan, A., \& Wilke, C. B. (2006). Reforming the German public pension system, American Economic Association Annual Meeting, Boston, MA, 2014. Mannheim Research Institute for the Economics of Aging.

Bontje, M. (2005). Facing the challenge of shrinking cities in East Germany: The case of Leipzig. GeoJournal, 61(1), 13-21.

Botsch, E. (2015). The policy on gender equality in Germany (No. PE 510.025). Brussels, Belgium: European Parliament.

Central Intelligence Agency. (n.d.). Population below poverty line. Retrieved October 23, 2017, from https://www.cia.gov/library/publications/the-world-factbook/fields/2046.html

Christopher, K., England, P., Smeeding, T. M., \& Phillips, K. R. (2002). The gender gap in poverty in modern nations: single motherhood, the market, and the state. Sociological Perspectives, 45(3), 219-242.

Deutscher Bundestag. (2015). Strategische Sozialberichterstattung 2015: Unterrichtung durch die Bundesregierung (No. Drucksache 18/4500). Berlin, Germany: Deutscher Bundestag.

European Commission. (2012). The current situation of gender equality in Germany. Retrieved October 24, 2017, from http://ec.europa.eu/justice/gender-equality/files/epo_campaign/country-profile_germany_en.pdf

European Commission. (2017). 2017 report on equality between women and men in the EU. Retrieved October 24, 2017, from https://eeas.europa.eu/sites/eeas/files/2017_report_equality_women_men_in_the_eu_en.pdf

Finnish Centre for Pensions. (2010). Tracing old-age poverty--the significance of the household structure on gender differences in the poverty rate in eight EU countries (Working Paper No. 2010:7). Helsinki: Ahonen, K., \& Bach-Othman, J.

Huinink, J., \& Mayer, K. U. (1995). Family formation in West Germany. In K. Oppenheim Mason \& A. Jensen (eds.), Gender and Family Change in Industrialized Countries (pp. 200-222). Oxford, GB: Clarendeon Press.

Klammer, U. (2009). Germany: deviating from the male breadwinner norm. In G. Schaffner Goldberg (ed.) Poor women in rich countries: the feminization of poverty over the life course (pp. 94-120). New York, NY: Oxford University Press.

Organisation for Economic Co-operation and Development (n.d.). Inequality - poverty rate. Retrieved October 31, 2018, from http://data.oecd.org/inequality/poverty-rate.htm

Meyer-Rosenfeld, J. (2013). GRIN - Staatliche Maßnahmen gegen Kinderarmut. Eine Übersicht über die Situation in Deutschland. Retrieved October 24, 2017, from http://www.grin.com/de/e-book/337797/staatlichemassnahmen-gegen-kinderarmut-eine-uebersicht-ueber-die-situation

Nipper, J. (2002). The transformation of urban East Germany since the "Wende": from a socialist city to a ...?. Hommes et Terres Du Nord, (4), 63-74.

Organisation for Economic Co-operation and Development. (2016, March). OECD economic surveys: Germany 2016. Retrieved November 11, 2017, from http://www.keepeek.com/Digital-Asset-

Management/oecd/economics/oecd-economic-surveys-germany-2016/the-gender-earnings-gap-is-widebecause-many-women-work-few-hours_eco_surveys-deu-2016-graph12-en

Pfeiffer, S. (2014). Die verdrängte Realität: Ernährungsarmut in Deutschland: Hunger in der Überflussgesellschaft. Wiesbaden, Hessen: Springer VS.

Sattar, S.. (2012). Opportunities for men and women in emerging Europe and Central Asia. Retrieved October 24, 2017, from World Bank Group Website: 
http://documents.worldbank.org/curated/en/479131468250293544/pdf/659310WPOOPUBL065737B0Ge nderOReport.pdf Washington, D.C.

Sellach, B., \& Ender-Dragässer, U. (2000). Ursache und Umfang von Frauenarmut. Retrieved October 24, 2017, from Social Science Open Access Repository Website: https://www.ssoar.info/ssoar/handle/document/12575

Simler, K. (2016). Pinpointing poverty in Europe: New evidence for policy making. Retrieved October 24, 2017, from World Bank Group Web site:

http://documents.worldbank.org/curated/en/618561489646988000/Pinpointing-poverty-in-Europe-newevidence-for-policy-making

Skard, T. (2015). Women of power: half a century of female presidents and prime ministers. Bristol, GB: Policy Press.

Society for the Study of Economic Inequality. (2006, May). Poverty and women's labor market activity: the role of gender wage discrimination in the EU (ECINEQ WP 2006-40). Vigo, Spain: Gradin, C., del Rio, C., \& Canto, O.

Somaskanda, S. (n.d.). Rich Germany Has a Poverty Problem. Retrieved October 23, 2017, from Foreign Policy Web site: https://foreignpolicy.com/2015/05/05/rich-germany-has-a-poverty-problem-inequality-europe/

United Nations Entity for Gender Equality and the Empowerment of Women. (n.d.). Gender mainstreaming. Retrieved November 26, 2017, from http://www.un.org/womenwatch/osagi/gendermainstreaming.htm

United Nations Entity for Gender Equality and the Empowerment of Women. (n.d.). Germany pledges to expand support for women's professional skills in developing countries, and require corporate boards at home to apply a 30 per cent quota for women. Retrieved October 20, 2017, from

http://www.unwomen.org/en/get-involved/step-it-up/commitments/germany 